\title{
Managing Organizational Knowledge: An Empirical Study in Jordanian Pharmaceutical Industry
}

\author{
Khaled Mohammad Ahmad Algharibeh \\ Applied Science University, Kingdom of Bahrain
}

\begin{abstract}
:
Enabling knowledge creation (EKC) is an important issue in knowledge society. This study empirically examines the relationship between enabling knowledge creation and knowledge conversion in Jordanian pharmaceutical industry. Currently, managers need to support knowledge creation process rather than control it. Enablers knowledge may be able this. Previous studies have not clearly identified nor demonstrated the relationship between the enabler's knowledge and the knowledge conversion. This study is focusing on the question what are the enabler's knowledge that effects on the knowledge conversion. The purpose of this research is to identify if a positive relationship between the enabler's knowledge and the knowledge conversion. A positivistic approach was adapted using quantitative data. A survey aimed at employees in Jordanian pharmaceutical industry population was conducted in an effort to investigate the knowledge conversion and to examine the relationship of enabler's knowledge and the improvement of knowledge conversion.
\end{abstract}

Keywords: Knowledge Management; Knowledge Creation; Pharmaceutical Business Managers.

\section{Introduction}

In today's economy, knowledge includes knowing about people, money, leverage, learning, flexibility, power and competitive advantage. Drucker (1993) wrote that "Knowledge has become the key economic resource and the dominant and perhaps even the only -source of competitive advantage". In this said two concepts - knowledge as an economic resource and knowledge as a source of competitive advantage -made significant impact on the traditional management approach and demanded a paradigm shift. Knowledge is more relevant to sustained business than capital labor or land. Nevertheless, it remains the most neglected asset. It is more than justified true believe and essential for action, performance and adoption, knowledge provides the ability to respond to novel situation. Most organizations realized that knowledge is a source of competitive advantage and a primary factors in knowledge- based economy In other words, it is to deal astutely with knowledge, which has been stressed by Drucker (1993), Nonaka and Takeuchi (1995). Many organizations begin research about support knowledge conversion rather than control it. Many organizations begin their knowledge management efforts by trying to understand what, where support knowledge conversion and how support knowledge creation process. Evidently, this leads to the question how can knowledge enablers support the knowledge creation process?

Many studies were presented to knowledge conversion process For example:

Nonaka, Toyama and Konno (2000) proposed a model of dynamic knowledge creation comprising of three elements: The SECL process, involving the creation of knowledge by the conversion of tacit and explicit knowledge. "Ba" is the shared context for knowledge creation; and knowledge assets, consisting of the inputs, outputs and moderators

Copyright (C) 2010 Khaled Mohammad Ahmad Algharibeh. This is an open access article distributed under the Creative Commons Attribution License unported 3.0, which permits unrestricted use, distribution, and reproduction in any medium, provided that original work is properly cited. Author contact: Khaled Mohammad Ahmad Algharibeh

e-mail: Khaledalgaribeh @yahoo.com 
of the knowledge creation process. They discuses three elements as following The SECI process: There are four modes of knowledge conversion. They are: (1) socialization (from tacit knowledge to tacit knowledge); (2) externalization (from tacit knowledge to explicit knowledge); (3) combination (from explicit knowledge to explicit knowledge); and (4) internalization (from explicit knowledge to tacit knowledge). They see leadership link between SECI and (ba).They describe the knowledge-creating process as the dynamic interaction between organizational members, and between organizational members and the environment.

Nonaka, Toyama and Nagata (2000) see that the knowledge conversion rate is determined by such factors as knowledge vision, organizational structure, incentive system, corporate culture, routines and leadership. they focused on a firm creates knowledge continuously und dynamically though the SECL process, in which tacit knowledge held by individuals is converged and amplified by the spiral of knowledge through socialization, Externalization, Combination and Internalization. They argue that knowledge and the capability to create and utilize such knowledge are the most important source of a firm sustainable competitive advantage. They proposed that (ba) is becomes necessary to create knowledge-out of information and the ba gives shared context to the SECL process. The knowledge vision gives a direction to the knowledge-creating process and the knowledge created in it by asking such fundamental questions as "What are we?"e, "What should we create?"e „How can we do it?"e, „Why are we doing this?"e and "Where are we going?ee The knowledge vision defines the value system that evaluates, justifies and determines the quality of knowledge that the network creates. they argue that the production and reproduction of (ba) (i.e.,"a shared context in motion") is essential for organizational knowledge creation and , as (ba) is a place where information is given meaning through interpretation to become knowledge, and new knowledge is created out of existing knowledge through the change of the meanings and the contexts" (p.8).

Nonaka (1994) argues that organizational knowledge is created through continuous dialogue between tacit and explicit knowledge. Also, he says that knowledge creation occurs through a spiral interaction between the epistemological and ontological dimensions of knowledge. His is assumption that knowledge is created through conversion between tacit and explicit knowledge allows us to postulate four different mode of knowledge conversion: 1 - from tacit knowledge to tacit knowledge, 2- from explicit knowledge to explicit knowledge, 3- from tacit knowledge to explicit knowledge, 4- from explicit knowledge to tacit knowledge. He defined information is flow messages while knowledge is created and organized by the very flow of information.

Nonaka and Toyama (2005) presented a typology of organizational knowledge based on the interaction between subjectivity, objectivity and synthesis. They focused on seven bases of knowledge creation that consisted the following: knowledge vision, driving objective, which gives direction and energy to the SECL process, the SECL process dialogues and practice, (ba) an existential place for the SECL process, knowledge assets, which are inputs and outputs of the SECL process and environment as an ecosystem of knowledge. Also Knowledge is created through the synthesis of thinking and actions of individuals .They said that the theory of knowledge creation is based on an idealistic pragmatism which synthesizes the rational pursuit of appropriate ends. They grave the main role for the leadership on knowledge vision and ba. This study is an attempted to establish the theory of knowledgecreating firms to explain the complex process of knowledge being created organizationally.

Al- Taher (2007) in the thesis entitled innovation and knowledge transfer in Jordan pharmaceutical industry. The study aimed to develop and test a model of the determinants of knowledge transfer and innovation in Jordanian pharmaceutical industry. The study had shown significant relationships between knowledge transfer and innovation, also, there is positive retaliation between reflection and knowledge transfer, there is positive retaliation between dialogue and knowledge transfer and there is positive retaliation between double loop learning and knowledge transfer.

Von Krogh et al ,,2000) list five enablers for strategy and knowledge creation: instill a Knowledge Vision, Manage Conversations, and Mobilize Knowledge Activists, Create the Right Context and Globalize Local Knowledge. They argue that managers need to support knowledge creation rather than Control it. They explain enabler's knowledge as following: that knowledge 
vision is encouraged to create new knowledge and determined mission, Manage conversation which helps to share tacit knowledge process. They believe that "good conversations are the cradle of social knowledge in any organization (...), they allow the first and most essential step of knowledge creation: sharing tacit knowledge within amicrocommunity" Knowledge Activists are persons that facilitates the knowledge creation process, the create right context and globalize local knowledge aims at transferring locally created knowledge throughout the perhaps globally distributed company. They argue also that shared context is place such place can be "physical, virtual, mental, or- more likely- all three" (2000, P7).

Lee and Choi (2003) looked at three major factors for managing knowledge: enablers, processes, and organizational performance. Enablers are influencing factors that help foster knowledge consistently through the firm by stimulating knowledge creation, protecting knowledge, and facilitating the sharing of knowledge. Knowledge processes are knowledge management activities that help create a coordination structure that manages knowledge effectively. they divide the enablers into seven enablers: (1) collaboration degree of active support and help in an organization; (2) trust - degree of reciprocal faith in others ${ }^{\text {ee }}$ intentions, behaviors, and skills toward organizational goals; (3) learning - degree of opportunity, variety, satisfaction, and encouragement for learning and development in an organization; (4) centralization - degree of authority and control over decisions; (5) formalization - degree of formal rules, procedures, and standard polices; (6) T-shaped skills - degree of understanding of his or her own and others task areas; and (7) information technology support - degree of IT support for collative work, for communication, for searching and accessing, for simulation and prediction, and for systematic storing. They found collaboration; trust, learning, and centralization are significant (.05 significance level) predictors for knowledge creation. Collaboration is positively related with socialization, externalization, and internalization and not related to combination. Trust is related to all knowledge creation modes. Learning is related to socialization and internalization. Centralization is negatively related to socialization, externalization, and internalization while not related to combination. Formalization and Tshaped skills of members are not related to knowledge creation. IT support is significantly related to knowledge combination only. Then knowledge creation is positively related to organizational creativity, which is positively related to organizational performance.

Aurum et al., (2007) divide the knowledge management enablers into four enablers, leadership, technology, culture and measurement. They considered leadership and technology are to be the most significant as top-down KM strategies and mechanism knowledge management. They argue that leadership evaluates the role of leadership in managing knowledge within the organization. Culture is concerned with the climate of the knowledge sharing environment, as well as the culture in the organization that promotes the knowledge sharing. Technology examines the technology aspect of KM practice. Measurement aims to find out if there are effective measures to indicate the success or failure of KM practice in organization.

A study by Von krogh et al , (1997) on "knowledge activists " defined knowledge activists as someone ,some group or department that take on particular responsibility for energizing and coordinating knowledge creation efforts through out the corporation . The study aimed at explains the role of knowledge activists in the knowledge creation company as: catalysts of knowledge creation, connectors of knowledge creation initiatives and merchants of foresight. They note activism help to reduce the time and cost that needed for knowledge creation process, in addition its enabler.

This paper is organized into 4 sections: Section 1 will discuss on knowledge conversion and enablers knowledge. Section 2 will discuss the research design. Section 3 is the findings and Section 4 is conclusion.

\section{Research Design and Methodology Hypothesis Development}

This paper examines the enablers knowledge in two ways. The first one is to examine the knowledge enablers effect on knowledge creation process. knowledge conversion consist four basic modes (1) socialization (from tacit knowledge to tacit knowledge); (2) externalization (from tacit knowledge to explicit knowledge); (3) combination (from explicit knowledge to explicit knowledge); and (4) internalization (from explicit 
knowledge to tacit knowledge) Nonaka, Toyama and Konno (2000).while knowledge enablers are (knowledge vision , knowledge objectives information technology, shared context (ba), culture organization, structure organization, knowledge activist , knowledge leadership, manage conversation). Von Krogh et al (2000) argue that that "good conversations are the cradle of social knowledge in any organization (...), they allow the first and most essential step of knowledge creation: sharing tacit knowledge within amicrocommunity" Knowledge enablers can be described five enablers: instill a Knowledge Vision, Manage Conversations, and Mobilize Knowledge Activists, Create the Right Context and Globalize Local Knowledge (Von Krogh et al 2000).Based on Lee and Choi (2003) and Von Krogh et al (2000) research, There is significant effect of knowledge enablers on knowledge creation process in Jordanian pharmaceutical industries. Therefore organizations need to support knowledge creation process rather than control it.
H1: There is significant effect of knowledge enablers on knowledge conversion in Jordanian pharmaceutical industries.

The second way is to examine the enablers knowledge effect on (socialization, externalization, combination, internalization). Lee and Choi (2003) stress that Enablers are influencing factors that help foster knowledge consistently through the firm by stimulating knowledge creation, protecting knowledge, and facilitating the sharing of knowledge. The process of knowledge creation can only be enabled or supported by an "overall set of organizational activities that positively affect knowledge creation" (von Krogh et al. 2000, p. vii). Thus, it is necessary to support knowledge creation process through enabler knowledge.

H2: There is significant effect of knowledge enablers on (socialization, externalization, combination, internalization).

Based on the literature review and hypotheses developed, a framework - to guide the study - was developed as in Figure 1

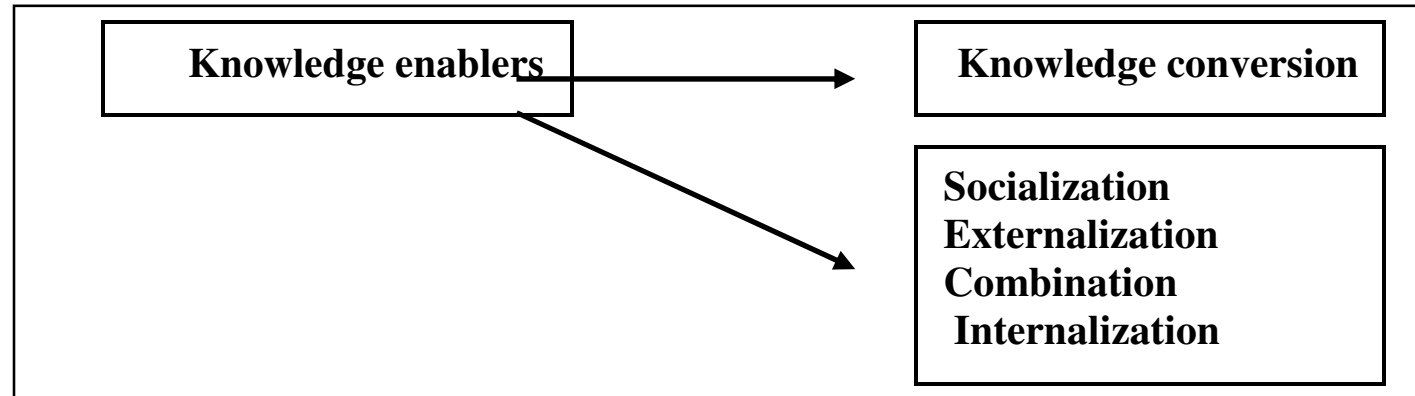

Figure 1: Proposed Mode

\subsection{Data and Measures}

The aim of this study is to evaluate the effects of knowledge enablers on knowledge creation process. Knowledge enablers was measured at following: Items knowledge vision were developed and constructed based on some researchers that interested in knowledge vision as Von Krogh et al ,(2000), Nonaka et al (2000a), Nonaka and Toyama (2005), Nonaka et al (2003). Items knowledge objectives were developed and constructed based on some researchers that interested in knowledge objectives as Nonaka and Takeuchi (1995), Nonaka and Toyama (2005).
Items information technology were designed based on some studies as Hein (2004), Brink (2003) and others. Items Manage conversation were designed based on some researchers as Von Krogh et al (2000), Mengies and Eppler (2005). Items shared context were designed based on some researchers as Von Krogh et al. (2000), Nonaka et al (2000a), Nonaka and Toyama. (2005), Nonaka et al. (2003) Nonaka et al. (1998). Organizational structure was measured using items from Lin Wen-bao (2007). Organizational culture was measured using items from Lin Wenbao (2007). Items Knowledge leadership based on some studies as Von Krogh et al (2000), Nonaka et 
al (2000a), Nonaka and Toyama (2005). Items Knowledge activists activists based on some studies as Von Krogh et al (1997), Von Krogh et al. (2000).finally, Knowledge conversion was measured using items from Nonaka et al. (2000a).All items were measured on a seven point Likert-type scale where 1 = strong disagree and 5 =strongly agree.

The research society contains (17) pharmaceutical companies. We selected (11) companies out of this society. Selection of each company depended on more than one point such as: Established year, the company should have at least 5 years. Capital of the company shouldn't less than 5 million. Number of employees in the company shouldn't less than 50 employees. Certification of IS9001 or IS 9002.

The Questionnaires were sent to 182 employees working in these only eleven companies. Only
(137) were returned. The overall response rate for this study was $84 \%$. This is regarded as relatively high, since the respondents are managers and they supposed to be too busy to answer Questionnaire. A Questionnaire was sent to respondents are manager, department head and Assistant manager currently working in the companies.

\subsection{Results and Discussion}

The reliability test was carried out to determine the reliability of the questions. Reliability analysis provides information about the relationships between individual items in a scale. When a previously validated instrument has been adopted, a higher cutoff value of 0.7 or higher may be Used (Nunnaly, 1978). Since all the Cronbach"s Alpha values are over the critical point of 0.7 shows that the surveyes reliability is accepted.

\begin{tabular}{|l|c|c|}
\hline \multicolumn{1}{|c|}{ Variables } & Item & $\begin{array}{c}\text { Cronbach } \\
\text { Alpha }\end{array}$ \\
\hline Knowledge vision enabler & 5 & 0.866 \\
\hline Goals enabler & 3 & 0.820 \\
\hline Technology enabler & 3 & 0.866 \\
\hline Manage conversation enabler & 3 & 0.923 \\
\hline Shared context (ba) enabler & 4 & 0.879 \\
\hline Organizational structure & 7 & 0.953 \\
\hline Organizational culture & 9 & 0.885 \\
\hline Knowledge leadership enabler & 4 & 0.892 \\
\hline Knowledge activists enabler & 3 & 0.923 \\
\hline Knowledge conversion & 20 & 0.920 \\
\hline
\end{tabular}

The result reveals strong correlations in all Knowledge enablers and knowledge conversion. The correlation data is shown in the Table 2 . 
Table 2: Correlation of Knowledge enablers and knowledge conversion

\begin{tabular}{|l|l|l|l|l|l|l|l|l|l|l|l|l|l|}
\hline VAR & VISIN & OBJECT & INFOR & MANA & CONT & STRUC & CULT & LEAD & ACIV & CON & SOCI & EXTR & COM \\
\hline VISION & $.605^{* *}$ & & & & & & & & & & & & \\
\hline OBECT & $.251^{* *}$ & $.376^{* *}$ & & & & & & & & & & & \\
\hline INFOR & .218 & $.215^{* *}$ & $.456^{* *}$ & & & & & & & & & & \\
\hline MANA & $.358^{* *}$ & $.422^{* *}$ & $.383^{* *}$ & $.503^{* *}$ & & & & & & & & & \\
\hline CONT & $.493^{* *}$ & $.675^{* *}$ & $.349^{* *}$ & $.310^{* *}$ & $.671^{* *}$ & & & & & & & & \\
\hline STRUC & $.570^{* *}$ & $.652^{* *}$ & $.473^{* *}$ & $.283^{* *}$ & $.610^{* *}$ & $.746^{* *}$ & & & & & & & \\
\hline CULT & $.486^{* *}$ & $.561^{* *}$ & $.388^{* *}$ & $.396^{* *}$ & $.581^{* *}$ & $.623^{* *}$ & $.620^{* *}$ & & & & & & \\
\hline LEADR & $.347^{* *}$ & $.334^{* *}$ & $.226^{* *}$ & $.517^{* *}$ & $.471^{* *}$ & $.399^{* *}$ & $.436^{* *}$ & $.622^{* *}$ & & & & & \\
\hline ACIVI & $.461^{* *}$ & $.562^{* *}$ & $.441^{* *}$ & $.388^{* *}$ & $.452^{* *}$ & $.574^{* *}$ & $.578^{* *}$ & $.604^{* *}$ & $.499^{* *}$ & & & & \\
\hline CONV & $.326^{* *}$ & $.459^{* *}$ & $.411^{* *}$ & $.304^{* *}$ & $.382^{* *}$ & $.473^{* *}$ & $* 507^{* *}$ & $.532^{* *}$ & $.407^{* *}$ & $.855^{* *}$ & & & \\
\hline SOCI & $.448^{* *}$ & $.496^{* *}$ & $.309^{* *}$ & $.365^{* *}$ & $.435^{* *}$ & $.561^{* *}$ & $.505^{* *}$ & $.521^{* *}$ & $.387^{* *}$ & $.859^{* *}$ & $.654^{* *}$ & & \\
\hline EXTRN & $.329^{* *}$ & $.465^{* *}$ & $.420^{* *}$ & $.375^{* *}$ & $.396^{* *}$ & $.447^{* *}$ & $.478^{* *}$ & $.421^{* *}$ & $.452^{* *}$ & $.844^{* *}$ & $.630^{* *}$ & $.604^{* *}$ & \\
\hline COMB & $.482^{* *}$ & $.507^{* *}$ & $.371^{* *}$ & $.285^{* *}$ & $.336^{* *}$ & $.492^{* *}$ & $.494^{* *}$ & $.603^{* *}$ & $.464^{* *}$ & $.872^{* *}$ & $.650^{* *}$ & $.700^{* *}$ & $.648^{* *}$ \\
\hline
\end{tabular}

** Correlation is significant at the 0.05 level

Hypothesis $\mathrm{H} 1$ examines effect of knowledge enablers on knowledge conversion. To investigate this relationship. There is significant effect of knowledge enablers on knowledge conversion. The proposed model is significant $(F=73.589$; $\mathrm{p}<0.00$ ); it explains $68 \%$ of variance in knowledge conversion. The knowledge objectives enablers, shared context and organizational culture are essential to support knowledge conversion especially Knowledge leadership enabler has a significant positive influence on knowledge conversion $(B=0.422$, $t$ value $=5.391, p<0.00)$.on ether hand, this study found that knowledge enablers as knowledge objective enabler, shared context, organizational structure and Knowledge leadership are supported knowledge conversion. While knowledge enablers as knowledge vision manage conversation, organization culture, information technology and knowledge activists are not supported knowledge conversion.
In hypothesis $\mathrm{H} 2$, it is to investigate the effect of knowledge enablers on (socialization, externalization, combination, internalization) process. This study found that Knowledge leadership is positively related with socialization and not related to externalization, combination, internalization. Organizational structure is positively related to externalization while not related to socialization, combination, internalization at significant $(.05$ level $)$ .knowledge objectives and Knowledge activists enablers are positively related with combination and not related to externalization, socialization, and internalization. While Information technology enabler are positively related with combination and not related to externalization, socialization, and internalization. This finding is also supported by Lee and Choi (2003) that found Information technology is positively related with combination and not related to externalization, socialization, 
and internalization. Finally, Knowledge leadership enabler is positively related with internalization and not related to externalization, socialization, and combination.

\subsection{Conclusion}

Based on the finding, there is positive effect of knowledge enablers on knowledge conversion process in Jordanian pharmaceutical industries. The primary hypothesis investigate that knowledge enablers as knowledge objective enabler, shared context, organizational structure and Knowledge leadership enablers are supported knowledge conversion. While knowledge enablers as knowledge vision manage conversation, organization culture, information technology and knowledge activists are not supported knowledge conversion. While second hypothesis investigate that that Knowledge leadership is positively related with socialization and not related to externalization, combination, internalization. Organizational structure is positively related to externalization while not related to socialization, combination, internalization at significant $(.05$ level) .knowledge objectives and Knowledge activists enablers are positively related with combination and not related to externalization, socialization, and internalization. While Information technology enabler are positively related with combination and not related to externalization, socialization, and internalization.

\section{Limitations of the study}

There are two main limitations that could arise from the research methods used. They are : (1) the cross-sectional research design of the survey; (2) the data set is limited to the Pharmaceutical industries.

The first limitation is the cross-sectional research design of the survey. This cross sectional study represents a slice of time, and does not show how employee's behavior may change over time.

Because our data set is cross-sectional in nature, we can only show associations, not causality, we cannot demonstrate the long-term sustainability of the relationships, and we cannot analyze longitudinal processes, such as knowledge conversion and the enablers ${ }^{e c}$ knowledge.

The second limitation is that this study focuses on one industry, the Pharmaceutical sector as one of the production industry. Although we have invested considerable effort in data collection, our data set is limited to the Pharmaceutical industry. We do not know how the results will be in other industries, although the systematic nature of our investigation adds to our belief that the framework can be extended to other industries.

\section{References}

AL- Tahaer, Asmahan (2007).innovation and knowledge transfer in Jordan pharmaceutical industry, The Arab Academy for Banking and Financial Sciences Faculty of Information Systems and Technology.

Brink, p. (2003). Social organizational and technological condition that enable knowledge sharing. A thesis presented to faculty of technology, policy and management at the Delft University of technology.

Drucker, P. (1993). Post-Capitalist Society. New York. Harper Business Dynamics.

Lin, Wen-bao. (2007) the effect of knowledge sharing model Expert system with application, 134 (2), 508- 1521.

Hein, E., (2004),"Knowledge Sharing on Tap". In side knowledge magazine. 7(9). [Online] [Retrieved ganuary2, 2008], Http: //www. Ik. Magazine, com

Nunnaly, J. (1978) Psychometric Theory, McGraw Hill, New York.

Nonaka, I. (1991) 'The Knowledge Creating Company'. Harvard Business Review, NovemberDecember, 96-104.

Nonaka, I and konno, N. (1998), "The Concept of Ba Building Foundation for Knowledge Creation,' California management Review, 40(3), 40-54.

Nonaka, I., Toyama, R. and Konno, N. (2000), 'SECI, Ba and Leadership: A Unified Model of Dynamic Knowledge Creation, 'Long Range Planning (32), 5-34.

Nonaka, I and Toyama, R. (2005),' The Theory of the Knowledge Creation Firm: Subjectivity, Objectivity and Synthesis. Industrial and corporate change,' 14(3), 419-436. 
Nonaka, I. and Takeuchi, H. (1995) the knowledge creating company, Oxford University press, New York.

Nonaka, I, Toyama, R. and A, Nagata. (2000), "A

firm As A Knowledge-Creating entity: A New Perspective on the Theory of the Firm," Industrial and corporate change 9, 1-20. [Online] [Retrieved ganuary12, 2009], http://icc.oupjournals.org/cgi/reprint/9/1/1.pdf

Nonaka, I., Toyama, R. and Byosiere, P. (2003). 'A theory of organizational knowledge creation: understanding the dynamic process of creating knowledge,'

Von Krogh, G., Ichijo, K. and Nonaka, I. (2000) Enabling Knowledge Creation. How to Unlock the Mystery of Tacit Knowledge and Release the Power of Innovation, Oxford Press.

Von Krogh, G, Nonaka, I. and Icijo, k. (1997), ' Develop knowledge activists,' European Management Journal 15 (5).

Von Krogh, G. (1998)."Care in knowledge creation"California Management Review, l (40), 133-153. 